\title{
Development of a Customized Autopilot for Unmanned Helicopter Model Using Genetic Algorithm via the Application of Different Guidance Strategies
}

\author{
A. Hosny ${ }^{*}$, M. Hosny ${ }^{\dagger}$, and H. Ez-Eldeen ${ }^{*}$
}

\begin{abstract}
The objective of this paper is to develop a customized autopilot system that enables a helicopter model to carry out an autonomous flight using on-board microcontroller. The main goal of this project is to provide a comprehensive controller design methodology, Modeling, simulation, guidance and verification for an unmanned helicopter model. The autopilot system was designed to demonstrate autonomous maneuvers such as flying over the planned waypoints with constant forward speed and considerable steep maneuvers. For the controller design, the nonlinear dynamic model of the Remote Control helicopter was built by employing Lumped Parameter approach comprising of four different subsystems such as actuator dynamics, rotary wing dynamics, force and moment generation process and rigid body dynamics. The nonlinear helicopter mathematical model was then linearized using small perturbation theory for stability analysis and linear feedback control system design. The linear state feedback for the stabilization and control of the helicopter was derived using Pole Placement Method. The overall dynamic system control with output feedback was computed using Genetic Algorithm. Series of Matlab-Simulink models and guidance algorithms were presented in this work to simulate and verify the autopilot system performance. The proposed autopilot has shown acceptable capability of stabilizing and controlling the helicopter during tracking the desired waypoints. This paper is presenting a detailed comparison study for two different guidance strategies. The first strategy is concerning the difference between the desired heading or elevation referred to the next waypoint and the actual heading or elevation of the unmanned helicopter model. The second strategy is concerning the relative distance between the actual and the desired trajectories. In other words the first method is tracking the waypoints while the second one is tracking the trajectory. In this work a comparison study was conducted through the mentioned strategies simulation to show the significant differences in the output performance. Some performance indexes were presented to evaluate the system performance errors and the control effort needed for both strategies using the same desired trajectory and the same waypoints.
\end{abstract}

Keywords: UAH unmanned aerial helicopter, RC Remote Control, PPM Pole Placement Method, GA Genetic Algorithm, DTCS Desired Trajectory Current Segment, WPTM Waypoint Tracking Method. TTM Trajectory Tracking Method, WPTM Waypoint Tracking Method, Jerk, FFR Fixed Frame of Reference, BFR Body Frame of Reference.

\footnotetext{
*Egyptian Armed Forces, Egypt, ahmed160771@yahoo.com

† Egyptian Armed Forces, Egypt, mbmomtaz@ hotmail.com

Egyptian Armed Forces, Egypt, hesham.ez@gmail.com 


\section{Helicopter Model}

Helicopter dynamics obey the Newton-Euler equations for rigid body in translational and rotational motions. The helicopter dynamics can be studied by employing lumped parameter approach which presents that the helicopter model shown in Fig. 1 as a composition of following components; main rotor, tail rotor, fuselage, horizontal bar and vertical bar. Figure 2 illustrates typical arrangement of component forces and moments generated in helicopter simulation model, $[1,2]$.

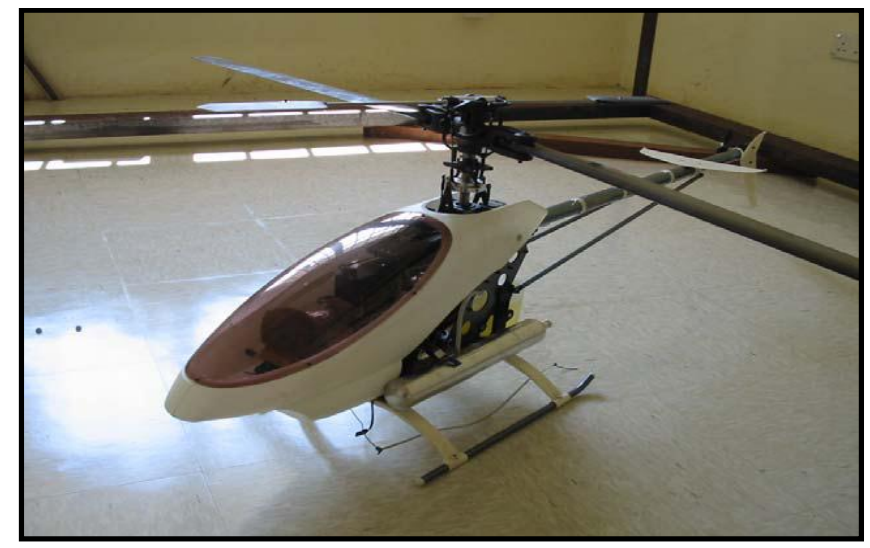

Fig. 1 Raptor 90 (15 cc Engine)

Forces equations:

$$
\begin{gathered}
\dot{u}=-(w q-v r)+\frac{X}{m}-g \sin \theta \\
\dot{v}=-(u r-w p)+\frac{Y}{m}+g \cos \theta \sin \varphi \\
\dot{w}=-(v p-u q)+\frac{Z}{m}+g \cos \theta \cos \varphi
\end{gathered}
$$

\section{Moment equations:}

$$
\begin{gathered}
I_{x x} \dot{p}=\left(I_{y y}-I_{z z}\right) \boldsymbol{q} r+I_{x z}(\dot{r}+p q)+L \\
I_{y y} \dot{q}=\left(I_{z z}-I_{x x}\right) r p+I_{x z}\left(r^{2}-p^{2}\right)+M \\
I_{z z} \dot{r}=\left(I_{x x}-I_{y y}\right) p q+I_{x z}(\dot{p}-q r)+N
\end{gathered}
$$

Kinematic equations:

$$
\begin{gathered}
\dot{\varphi}=p+q \sin \varphi \tan \theta+r \cos \varphi \tan \theta \\
\dot{\theta}=q \cos \varphi-r \sin \varphi \\
\dot{\Psi}=q \sin \varphi \sec \theta+r \cos \varphi \sec \theta
\end{gathered}
$$

The physical helicopter parameters used for the model (Raptor 90) are given in Table 1. 
Table 1 Parameters of Raptor 90 helicopter for simulation model

\begin{tabular}{|c|c|}
\hline Parameter & Description \\
\hline$\rho=1.225 \mathrm{~kg} / \mathrm{m}^{3}$ & Atmosphere density \\
\hline $\mathrm{m}=7.70 \mathrm{~kg}$ & Helicopter mass \\
\hline$I_{x x}=0.192 \mathrm{~kg} \mathrm{~m}^{2}$ & Rolling moment of inertia \\
\hline$I_{y y}=0.34 \mathrm{~kg} \mathrm{~m}^{2}$ & Pitching moment of inertia \\
\hline$I_{z z}=0.280 \mathrm{~kg} \mathrm{~m}^{2}$ & Yawing moment of inertia \\
\hline$\Omega_{\mathrm{nom}}=162 \mathrm{rad} / \mathrm{s}$ & Nominal main rotor speed \\
\hline $\mathbf{R}_{\mathrm{M}}=\mathbf{0 . 7 7 5} \mathrm{m}$ & Main rotor radius \\
\hline $\mathbf{R}_{\mathrm{CR}}=0.370 \mathrm{~m}$ & Stabilizer bar radius \\
\hline$C_{M}=0.058 \mathrm{~m}$ & Main rotor chord \\
\hline $\mathrm{C}_{\mathrm{CR}}=0.06 \mathrm{~m}$ & Stabilizer bar chord \\
\hline$a_{M}=5.5 \mathrm{rad}^{-1}$ & Main rotor blade lift curve slope \\
\hline$C_{D o}^{M}=\mathbf{0 . 0 2 4}$ & Main rotor blade zero lift drag coefficient \\
\hline$C_{T \max }^{M}=0.00168$ & Main rotor max thrust coefficient \\
\hline$I_{\beta}=0.038 \mathrm{~kg} \mathrm{~m}^{2}$ & Main rotor blade flapping inertia \\
\hline $\mathbf{R}_{\mathrm{T}}=\mathbf{0 . 1 3 \mathrm { m }}$ & Tail rotor radius \\
\hline$C_{T}=0.029 \mathrm{~m}$ & Tail rotor chord \\
\hline$a_{T}=5.0 \mathrm{rad}^{-1}$ & Tail rotor blade lift curve slope \\
\hline$C_{D o}^{T}=0.024$ & Tail rotor blade zero lift drag coefficient \\
\hline$C_{T \max }^{T}=0.0922$ & Tail rotor max thrust coefficient \\
\hline$n_{T}=4.66$ & Gear ratio of tail rotor to main rotor \\
\hline $\mathrm{n}_{\mathrm{es}}=9.0$ & Gear ratio of engine shaft to main rotor \\
\hline$\delta_{T}^{\text {trim }}=0.1 \mathrm{rad}$ & Tail rotor pitch trim offset \\
\hline$S_{V}=0.012 \mathrm{~m}^{2}$ & Effective vertical fin area \\
\hline$S_{H}=0.01 \mathrm{~m}^{2}$ & Effective horizontal fin area \\
\hline$C_{L \propto}^{V}=2.0 \mathrm{rad}^{-1}$ & Vertical fin lift curve slope \\
\hline$C_{L \propto}^{H}=3.0 \mathrm{rad}^{-1}$ & Horizontal tail lift curve slope \\
\hline$S_{x}^{F}=\mathbf{0 . 1} \mathbf{~ m}^{2}$ & Frontal fuselage drag area \\
\hline$S_{y}^{F}=0.22 \mathrm{~m}^{2}$ & Side fuselage drag area \\
\hline$S_{Z}^{F}=\mathbf{0 . 1 5} \mathbf{~ m}^{2}$ & Vertical fuselage drag area \\
\hline$h_{M}=0.235 \mathrm{~m}$ & Main rotor hub height above $\mathrm{CG}$ \\
\hline$l_{M}=0.015 \mathrm{~m}$ & Main rotor hub behind CG \\
\hline $\mathrm{l}_{\mathrm{T}}=0.91 \mathrm{~m}$ & Tail rotor hub location behind CG \\
\hline$h_{T}=0.08 \mathrm{~m}$ & Tail rotor height above $\mathrm{CG}$ \\
\hline$l_{H}=0.71 \mathrm{~m}$ & Stabilizer location behind CG \\
\hline $\mathrm{k}_{\mathrm{MR}}=\mathbf{0 . 3 3 3 3}$ & Amount of commanded swash plate tilt \\
\hline $\mathrm{k}_{\mathrm{CR}}=1.1429$ & $\begin{array}{l}\text { Geometry coefficient of the mechanical } \\
\text { linkage of control rotor and swash plate }\end{array}$ \\
\hline
\end{tabular}




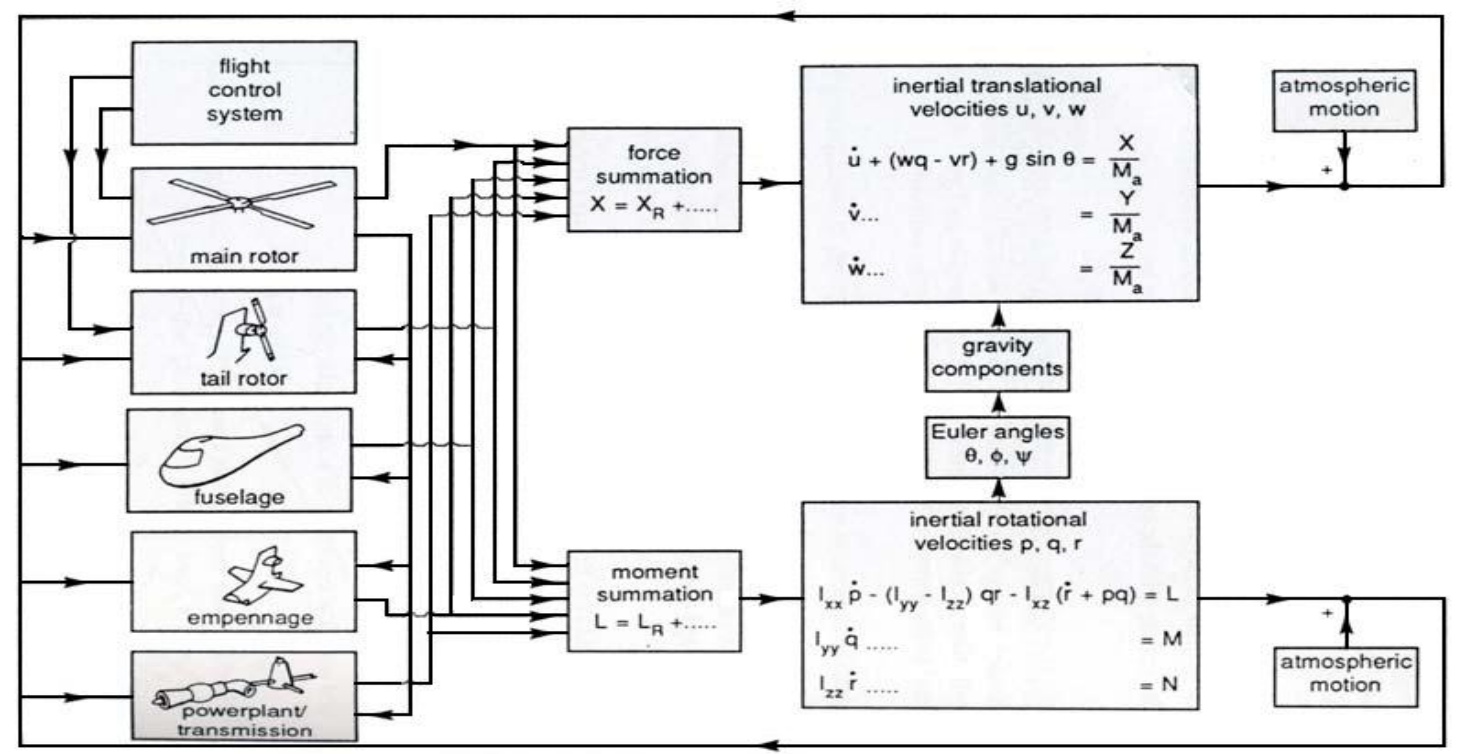

Fig. 2 Typical Arrangement of Component Forces and Moments Generation in 6-DOF Helicopter Simulation Model

The linearized matrices for hover condition excluding the control rotor (Six DOF model eight states) are given in Table 2 and Table 3. Each column and row is marked with the states and inputs that are being referred to the state space model. Table 4 states the stable and unstable eigenvalues according to the different modes for six DOF in hovering and low speed flight conditions. Figure 3 illustrates the different poles on the corresponding Pole-Zero Map.

$$
\begin{gathered}
\dot{x}=A x+B u \\
y=C x
\end{gathered}
$$

Table 2 Analytically obtained $\boldsymbol{A}$ matrix in hover with no control rotor

\begin{tabular}{c|c|c|c|c|c|c|c|c}
\hline \hline & $u$ & $w$ & $q$ & $\theta$ & $v$ & $p$ & $\varphi$ & $r$ \\
\hline \hline$u$ & -0.0070825 & 0 & 0.00093895 & -9.81 & -0.0009389 & -0.0292 & 0 & 0 \\
\hline$w$ & 0 & -0.8159 & 0 & 0 & 0 & 0 & 0 & -0.12 \\
\hline$q$ & 0.0377 & -0.2775 & -0.6718 & 0 & -0.28599 & 0.1558 & 0 & 0.265 \\
\hline$\theta$ & 0 & 0 & 1 & 0 & 0 & 0 & 0 & 0 \\
\hline$v$ & 0.00093895 & 0 & 0.0144 & 0 & -0.06808 & 0.122823 & 9.81 & 0.055 \\
\hline$p$ & 0.0094513 & 0 & -0.2942 & 0 & -0.1377 & -1.286 & 0 & 0.19 \\
\hline$\varphi$ & 0 & 0 & 0 & 0 & 0 & 1 & 0 & 0 \\
\hline$r$ & 0 & -1.5246 & 0 & 0 & 1.528 & 0.122 & 0 & -5.1868 \\
\hline
\end{tabular}

Table 3 Analytically obtained $B$ matrix in hover with no control rotor

\begin{tabular}{c|c|c|c|c}
\hline \hline & $\delta_{\mathrm{Col}}$ & $\delta_{\text {Lon }}$ & $\delta_{\text {Lat }}$ & $\delta_{\text {Ped }}$ \\
\hline \hline$U$ & 5.2981 & 1.5591 & -0.1816 & 0 \\
\hline$W$ & -128.777 & 0 & 0 & 0 \\
\hline$Q$ & -72.0367 & -8.3082 & 0.9678 & 9.07 \\
\hline$\Theta$ & 0 & 0 & 0 & 0 \\
\hline$V$ & -31.9088 & 0.0605 & -0.5196 & 5.055 \\
\hline$P$ & -321.1883 & 1.8281 & -15.6933 & 17.322 \\
\hline$\Phi$ & 0 & 0 & 0 & 0 \\
\hline$R$ & 178.2831 & 0 & 0 & 17.322 \\
\hline \hline
\end{tabular}


Table 4 Eigenvalues and modes for 6-DOF in Hovering/Low Speed Flight Condition

\begin{tabular}{l|c|c|c}
\hline \multicolumn{1}{c|}{ Mode } & Eigenvalues & Damping & Frequency $(\mathrm{rad} / \mathrm{s})$ \\
\hline \hline Longitudinal Oscillation & $0.169 \pm 0.392 \mathrm{i}$ & -0.395 & 0.427 \\
\hline Lateral Oscillation & $-0.0279 \pm 0.765 \mathrm{i}$ & 0.0365 & 0.765 \\
\hline Heave & $-0.68 \pm 0.142 \mathrm{i}$ & 0.979 & 0.695 \\
\hline Roll Subsidence & -1.68 & 1 & 1.68 \\
\hline Yaw & -5.28 & 1 & 5.28 \\
\hline
\end{tabular}

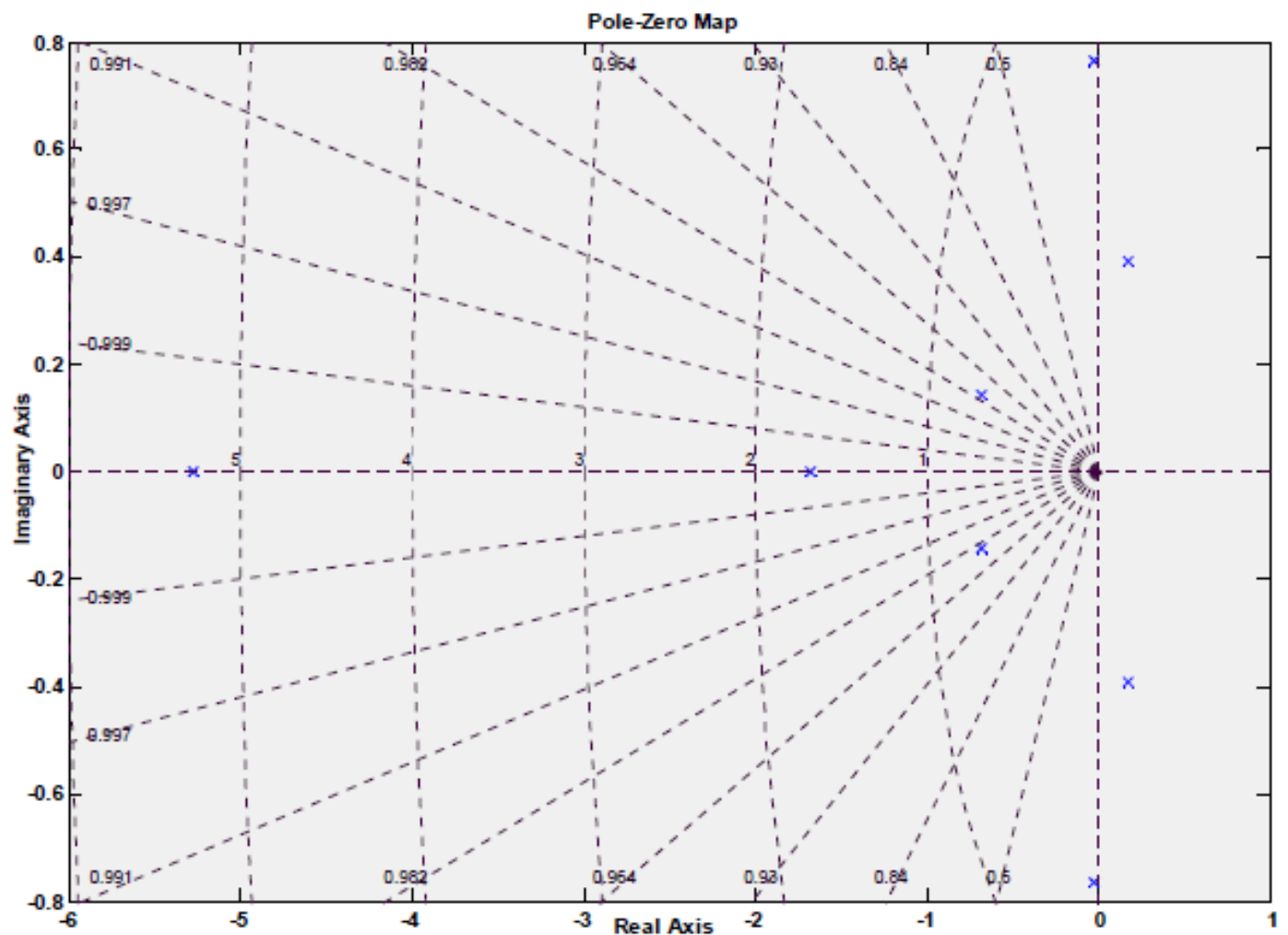

Fig. 3 Poles of Coupled Longitudinal and Lateral Motion for 6-DOF with no Control Rotor

\section{Application of Pole Placement Method to 6-DOF} (8 States Linear Model)

The objective of applying Pole Placement Method (PPM) to 6-DOF model is to shift the unstable Poles (the above marked ones) to the Left region of the root Locus (stable region). Consequently an initial stable reference model is established and ready to be tuned by applying GA functions to optimize the net performance index. The default poles will be placed in new position as the following $(-0.8 \pm 1.095 \mathrm{i},-0.85 \pm 1.096 \mathrm{i},-57,-10,-15,-10)$ according to the stated flying qualities in Fig. 4, [5]: 


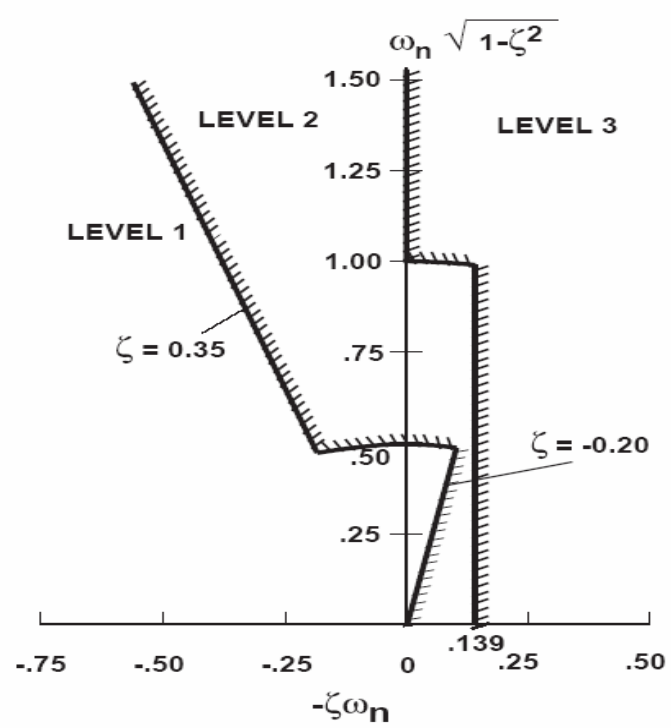

Fig. 4 Limits on pitch (roll) oscillations - hover and low speed according to Aeronautical Design Standard for military helicopter (ADS-33C)

(US Army Aviation Systems Command, 1989)

\section{Application of GA Functions to optimize the PID Controller Parameters}

The main objective of the proposed GA procedure is to optimize (minimize) the output performance index (maximize fitness function) of the whole integrated control system used in Fig. 5. An application of GA code combined with SIMULINK control model for the proposed Helicopter model is implemented to minimize the performance index $(J)$, [3].

The equation describing the net output performance $(J)$ is stated below:

$$
J=\int_{0}^{\infty}\left[\left|e\left(u_{-} \operatorname{sim}\right)\right| \cdot t^{2} \cdot W_{1}+\left|e\left(w_{-} \operatorname{sim}\right)\right| \cdot t^{2} \cdot W_{2}+\left|e\left(\varphi_{-} \operatorname{sim}\right)\right| \cdot t^{2} \cdot W_{3}+\left|e\left(r_{-} \operatorname{sim}\right)\right| \cdot t^{2} \cdot W_{4}\right] d t
$$

where

$e\left(u \_\right.$sim $)$is the forward speed error

$e\left(w_{-}\right.$sim $)$is the normal speed error

$e\left(\varphi \_s i m\right)$ is the bank angle error

$e\left(r_{-} \operatorname{sim}\right)$ is the yaw rate error

$W_{1}, W_{2}, W_{3}$ and $W_{4}$ are the performance weights that depend on the required performance priority.

The previous index can be obtained from the nonlinear simulation of the pitch control model consequently GA can use it as the fitness function.

\subsection{Optimizing PID Parameters}

\subsubsection{Using binary system coding}

Coding: using 10-bit binary genes to express $K_{P}, K_{I}, K_{D}$. For example $\left(K_{\mathrm{P}}\right)$ from bit 1 000000000(0), to bit 10 is $111111111(11023)$.Then string $K_{P}, K_{I}, K_{D}$ to 30-bit binary cluster. $x: 000011011111011100010000100010$ expresses a chromosome, the former 10-bit expresses $K_{P}$, the second portion expresses $K_{I}$ and the third one expresses the $K_{D}$.

Decoding: Cut one string of 30-bit binary string to three 10-bit binary string, then convert them to decimal system values $y_{1}, y_{2}$ and $y_{3},[3,4]$. 


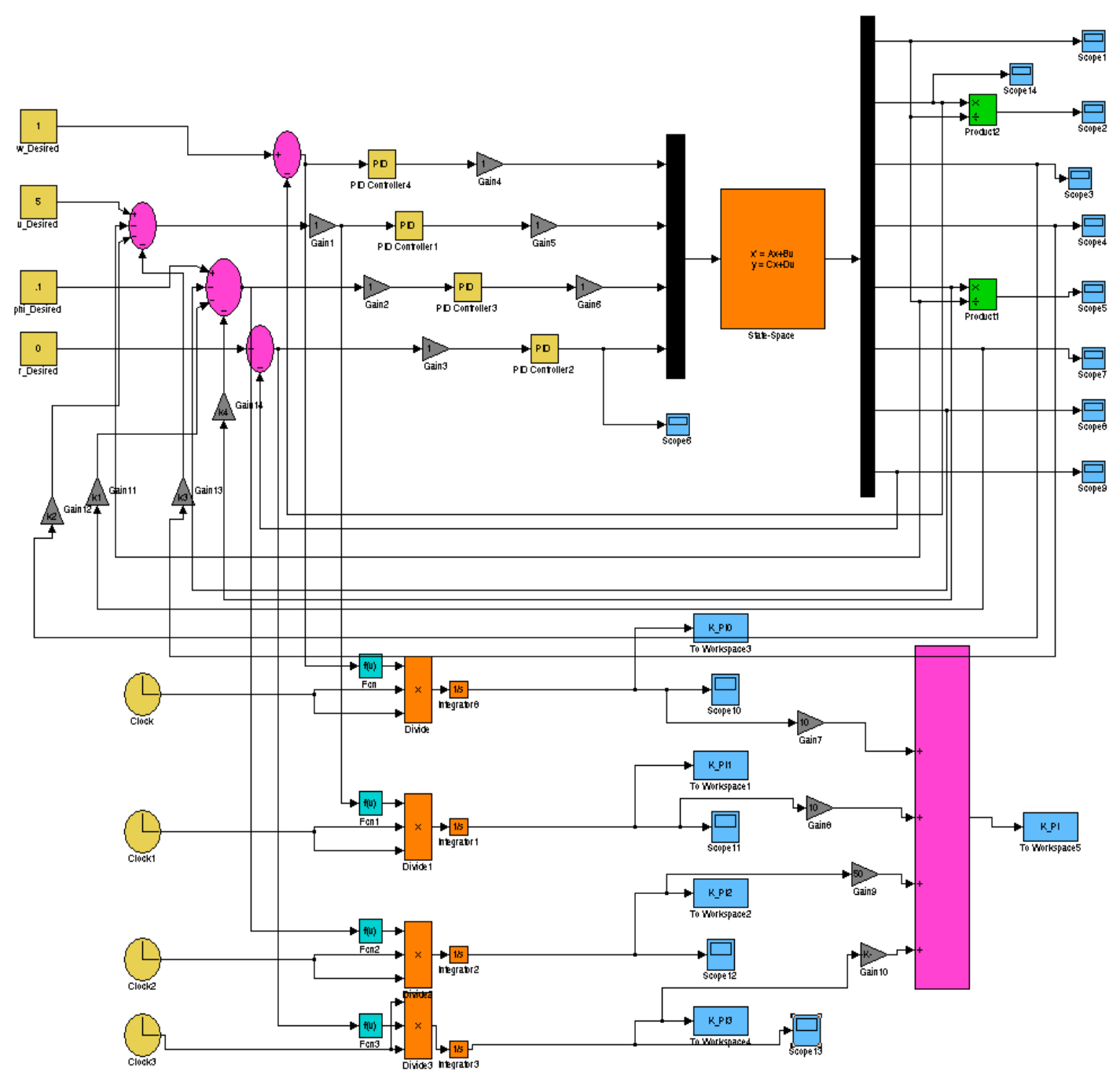

Fig. 5 Proposed Control System for Computing PID Optimum Gains

\subsubsection{Evaluation of fitness function}

Fitness function is the main criterion of the GA algorithm, as it represents how much the system is optimum and stable. The following equation describes the relation between the fitness function and the performance index.

$f\left(K_{P}, K_{I}, K_{D}\right)=\left(J\left(e_{-} \operatorname{sim}\right)\right)^{-1}$

\subsubsection{Design operators}

Proportion selection operator, single point crossover operator, basic bit mutation operator.

\subsubsection{Parameters of GA}

Population size is $M=40$, generation $G=100$, crossover probability $P_{\mathrm{c}}=0.60$, mutation probability $P_{\mathrm{m}}=0.10$. Adopting the above steps, after 100 steps iteration, Fig. 6, the best performance index will be reached giving the optimum gains as shown in Table 5. 


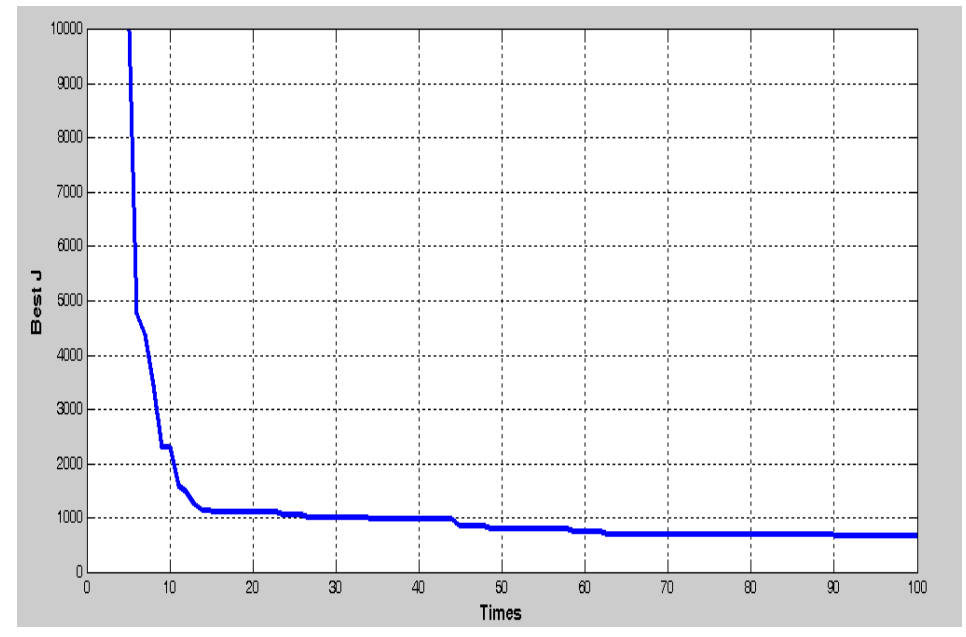

Fig. 6 Performance Index J after 100 iterations

Table 5 PID Optimum Gains for the Integrated Control System

\begin{tabular}{c|c|c|c|c|c|c|c}
\hline $\mathrm{k}_{1}$ & $\mathrm{k}_{2}$ & $\mathrm{k}_{3}$ & $\mathrm{k}_{4}$ & $\mathrm{k}_{\mathrm{p} 0}$ & $\mathrm{k}_{\mathrm{d} 0}$ & $\mathrm{k}_{\mathrm{i} 0}$ & $\mathrm{k}_{\mathrm{p} 1}$ \\
\hline \hline-0.7634 & -0.1711 & -0.9081 & -0.9902 & 0.0190 & 0 & -1.8034 & 4.6676 \\
\hline $\mathrm{k}_{\mathrm{d} 1}$ & $\mathrm{k}_{\mathrm{i} 1}$ & $\mathrm{k}_{\mathrm{p} 2}$ & $\mathrm{k}_{\mathrm{d} 2}$ & $\mathrm{k}_{\mathrm{i} 2}$ & $\mathrm{k}_{\mathrm{p} 3}$ & $\mathrm{k}_{\mathrm{d} 3}$ & $\mathrm{~K}_{\mathrm{i} 3}$ \\
\hline 0 & 4.6774 & 4.9022 & 0 & 2.9062 & 2.9120 & 0 & 3.0459 \\
\hline \hline
\end{tabular}

\section{Integrated Control System}

Building up the PID controller using the previous optimum gains stated in Table 5 (inner loop controller). Then a proposed guidance algorithm is established and fed with the flying model position from the GPS and the waypoints data (number of waypoints, locations and sequence). Applying vector analysis with mathematical aids, the relative heading and elevation with respect to the next waypoint will be calculated. Consequently the required change in heading and elevation will be fed to the PID controller (outer loop) after applying manual tuning to the out loop gains. Figure 7 demonstrates the current and the relative heading with respect to the next waypoint in the sequence. The guidance algorithm maintains the actual flight path not to fly in continuous loops around a definite waypoint by using some switching limiters such as acceptable circular error around the proposed waypoints and switching orthogonal liners. Figure 8 shows the integrated control system including (Helicopter Model, Guidance Algorithm and PID Controller) with the input commands and the output performance. The guidance algorithm was implemented using Matlab code, and all the simulation results were conducted using Simulink.

\section{Guidance Approach}

\subsection{TTM Trajectory Tracking Method}

This approach is concerning the relative distances such as the lateral and the vertical distances with respect to the desired trajectory current segment DTCS body axis Fig. 9. In this method (in case of lateral control) inner and outer loops will be required, the inner loop will control the yaw rate and the outer loop will be fed by the lateral relative distance with respect to the desired trajectory current segment DTCS body axis while the feedback signal will represent the change in the heading as the absolute heading is not useful in this case. Both the inner and the out loop gains will be tuned by several trials after system integration. This approach leads to minimize the relative distances between the actual flight path and the desired trajectory. 


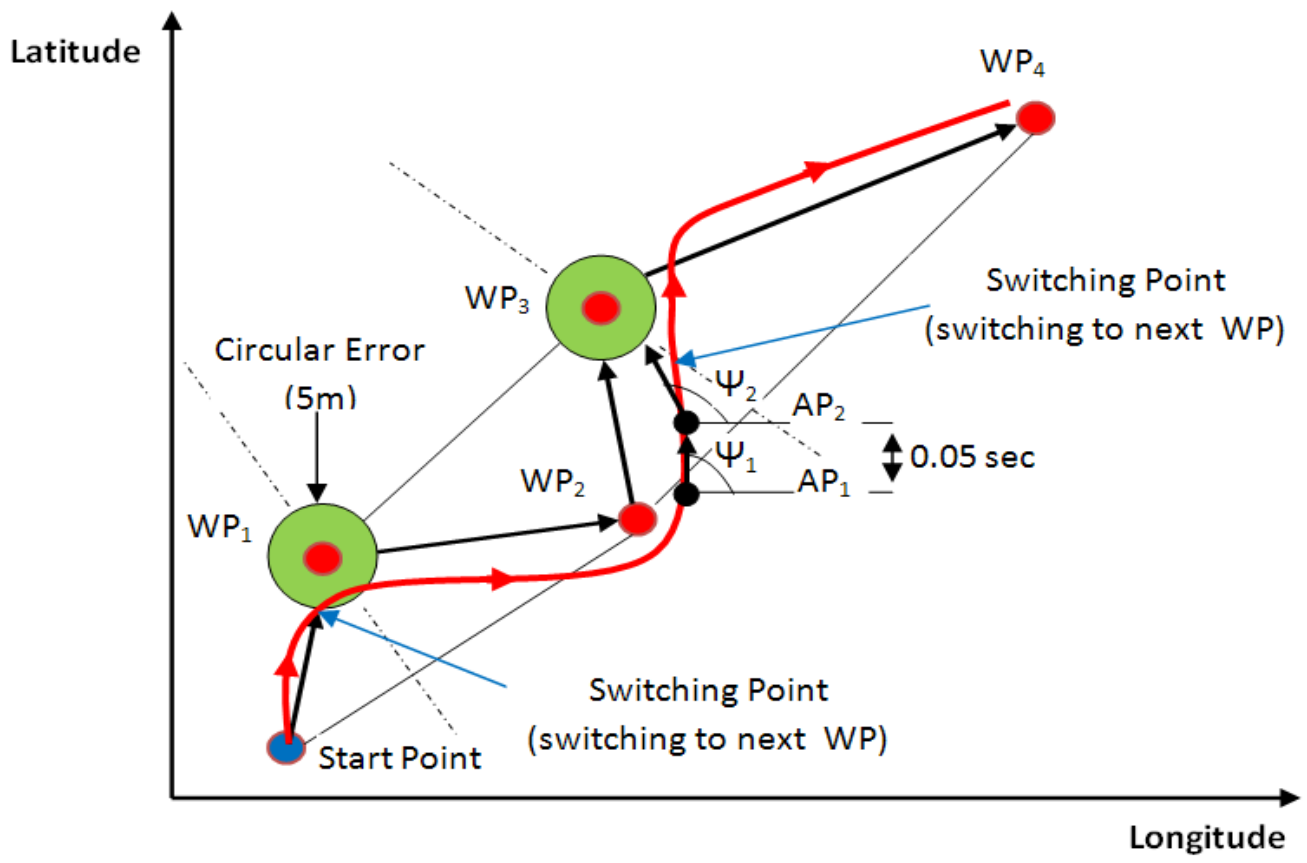

Fig. 7 Relative Heading using Waypoint Tracking Strategy

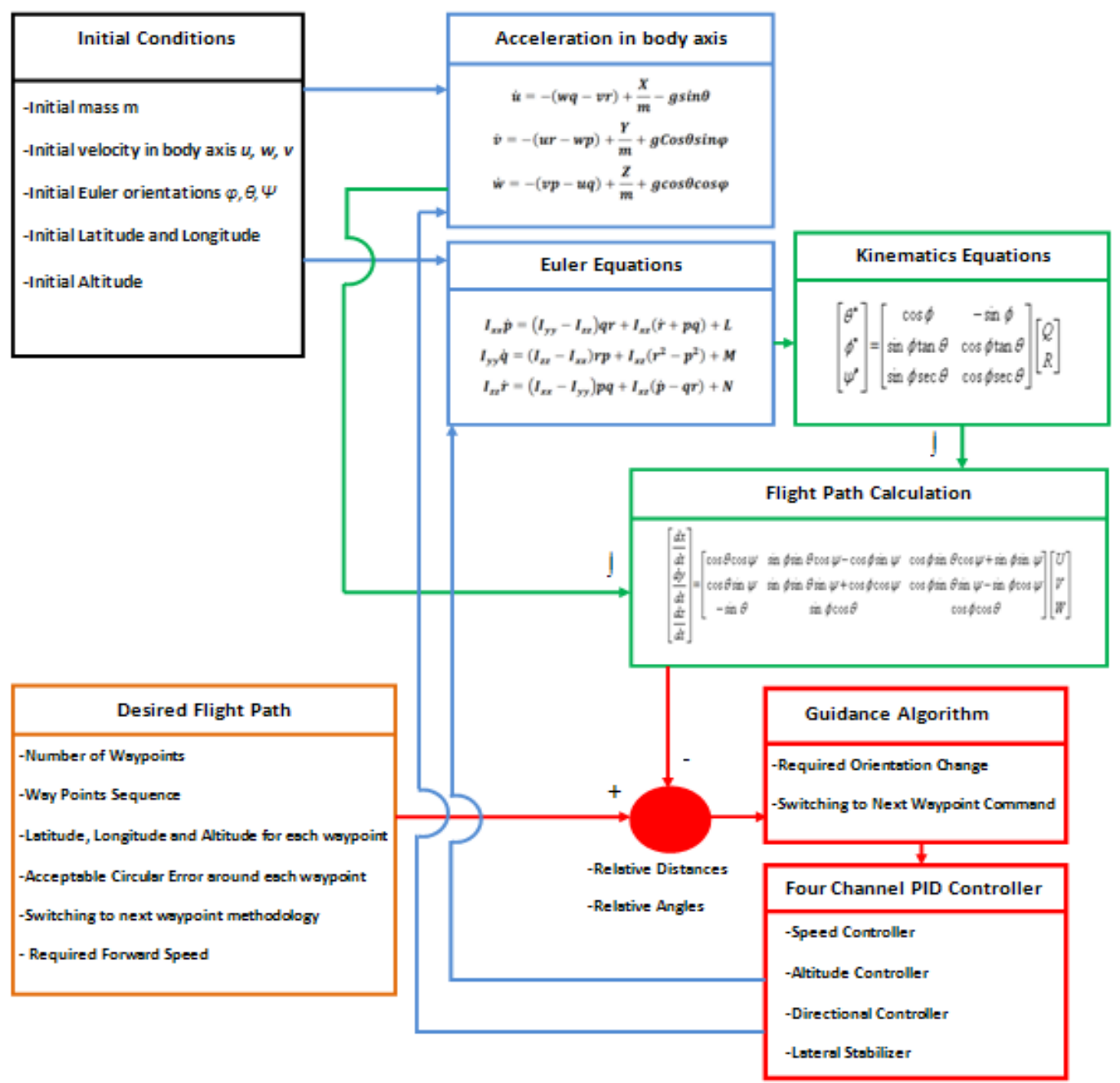

Fig. 8 Integrated Control System Including (Helicopter Model, Guidance Algorithm, PID Controller) 


\subsection{WPTM Waypoint Tracking Method}

This approach is concerning the relative heading and elevation with respect to waypoints, Fig. 10. Applying some vector analysis the required change in heading or elevation will be easily calculated, consequently they will be fed to the yaw rate inner loop after tuning the command input gain according to the performance criteria, [1].

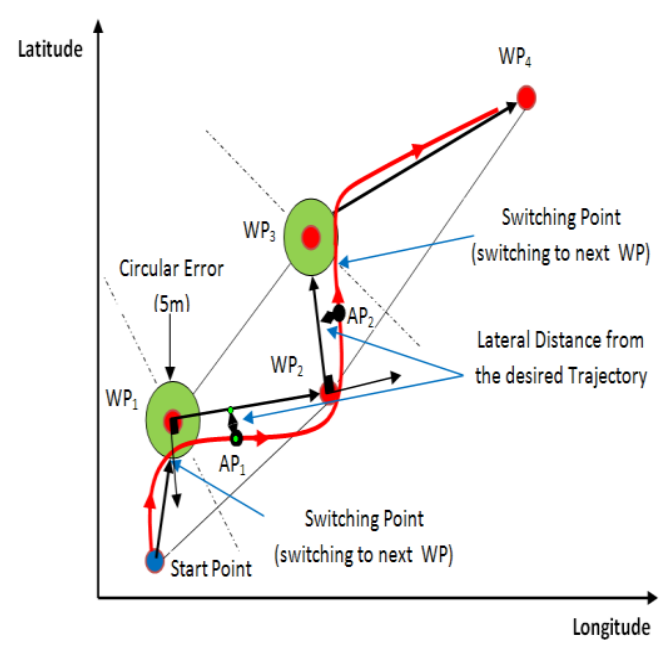

Fig. 9 Lateral Distances using Trajectory Tracking Strategy

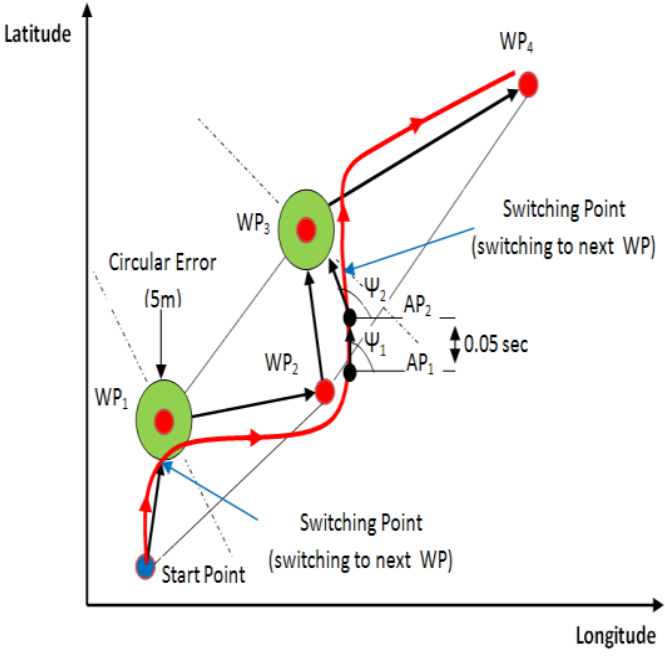

Fig. 10 Relative Heading using Waypoint Tracking Strategy

The following equations explain the transformation procedure starting from the actual flying model position with respect to fixed frame of reference to body coordinate of the DTCS with estimating a small initial conditions of ( 0.0001 for example) to avoid the singularities during simulation calculation, Fig. 11, [2,3].

X_T =Actual Flying Model Longitude (X component) relative to the fixed frame of reference $Y_{-} \mathrm{T}=$ Actual Flying Model Latitude ( $\mathrm{Y}$ component) relative to the fixed frame of reference $\mathrm{Z} \_\mathrm{T}=$ Actual Flying Model Altitude ( $\mathrm{Z}$ component) relative to the fixed frame of reference X_F =The Start Point of the Desired Trajectory Current Segment DTCS (X component) relative to the fixed frame of reference

Y_F = The Start Point of the Desired Trajectory Current Segment DTCS (Y component) relative to the fixed frame of reference

Z_F = The Start Point of the Desired Trajectory Current Segment DTCS (Z component) relative to the fixed frame of reference

$\mathrm{X}_{\mathrm{BO}}=$ Flying Model Actual Longitude $(\mathrm{X}$ component $)$ relative to DTCS body axes at the fixed frame of reference

$\mathrm{Y}_{\mathrm{BO}}=$ Flying Model Actual Latitude (Y component) relative to DTCS body axes at the fixed frame of reference

$\mathrm{Z}_{\mathrm{BO}}=$ Flying Model Actual Altitude ( $\mathrm{Z}$ component) relative to DTCS body axes at the fixed frame of reference

$\mathrm{X}_{\mathrm{B}}=$ Flying Model Actual Longitude (X component) relative to DTCS body axes

$\mathrm{Y}_{\mathrm{B}}=$ Flying Model Actual Latitude ( $\mathrm{Y}$ component relative) to DTCS t body axes

$\mathrm{Z}_{\mathrm{B}}=$ Flying Model Actual Altitude ( $\mathrm{Z}$ component) relative to DTCS body axes

$\theta, \Phi, \psi=$ Rotation around $\mathrm{X}, \mathrm{Y}, \mathrm{Z}$ axes
$\mathrm{A}=\cos \theta \cos \psi$
$\mathrm{B}=(\sin \Phi \sin \theta \cos \psi-\cos \Phi \sin \psi)$
$\mathrm{C}=(\cos \Phi \sin \theta \cos \psi+\sin \Phi \sin \psi)$ 
$\mathrm{D}=\cos \theta \sin \psi$

$\mathrm{E}=(\sin \Phi \sin \theta \sin \psi+\cos \Phi \cos \psi)$

$\mathrm{F}=(\cos \Phi \sin \theta \sin \psi-\sin \Phi \cos \psi)$

$\mathrm{G}=-\sin \theta$

$\mathrm{M}=\sin \Phi \cos \theta$

$\mathrm{N}=\cos \Phi \cos \theta$

$$
\begin{aligned}
& Z_{B O}=\frac{[(Y A-X D)(B G-M A)-(X G-Z A)(E A-B D)]}{[(F A-C D)(B G-M A)-(C G-N A)(E A-B D)]} \\
& Y_{B O}=\frac{\left[(Y A-X D)-Z_{B O}(F A-C D)\right]}{(E A-B D)} \\
& X_{B O}=\frac{\left(X-Y_{B O} B-Z_{B O} C\right)}{A} \\
& Z_{S H I F T}=\frac{\left[\left(Y_{F} A-X_{F} D\right)(B G-M A)-\left(X_{F} G-Z_{F} A\right)(E A-B D)\right]}{[(F A-C D)(B G-M A)-(C G-N A)(E A-B D)]} \\
& Y_{S H I F T}=\frac{\left[\left(Y_{F} A-X_{F} D\right)-Z_{S H I F T}(F A-C D)\right]}{(E A-B D)} \\
& X_{S H I F T}=\frac{\left(X_{F}-Y_{S H I F T} B-Z_{S H I F T} C\right)}{A} \\
& X_{\mathrm{B}}=X_{\mathrm{BO}}-X_{\text {shift }} \\
& \mathrm{Y}_{\mathrm{B}}=\mathrm{Y}_{\mathrm{BO}}-\mathrm{Y}_{\text {shift }} \\
& \mathrm{Z}_{\mathrm{B}}=\mathrm{Z}_{\mathrm{BO}}-\mathrm{Z}_{\text {shift }}
\end{aligned}
$$

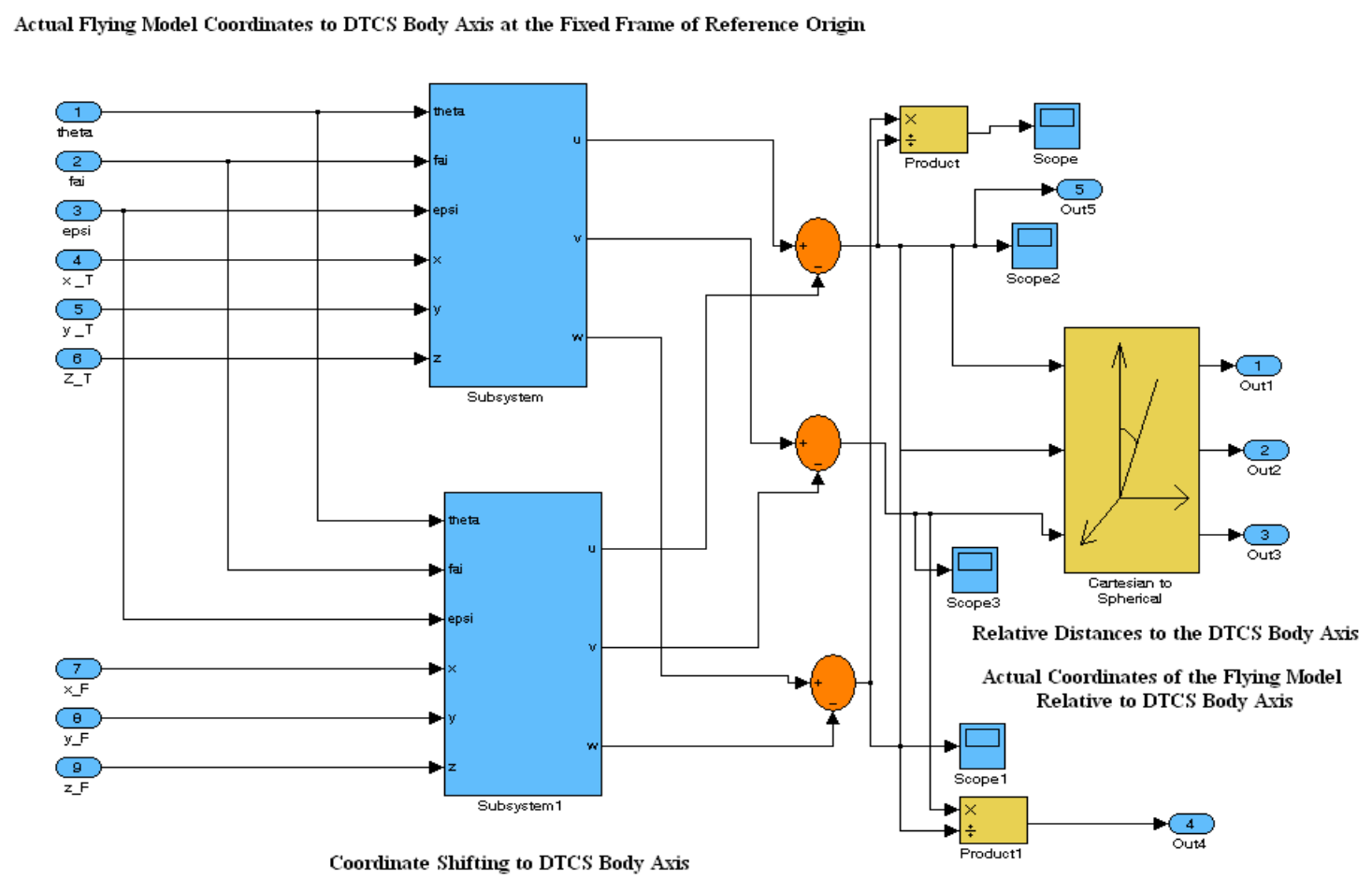

Fig. 11 Calculating the Flying Model Relative Distances with Respect to DTCS Body Axis 


\section{System Performance}

In the following figures (Fig. 12 through Fig. 31), it is clear that the Trajectory Tracking Method TTM has a great and obvious impact in minimizing the relative distance between the actual flight path and the desired trajectory, the figures show that the flying model almost flying stick to the desired path when TTM is used while it tracks the waypoints only when WPTM is used regardless the relative distances between the actual and the desired path, thus increasing the relative distances (relative errors) when WPTM is used compared to the relative distances if TTM is used. Figure $\mathbf{2 6}$ shows also a considerable fluctuation with large amplitude when TTM is used rather than when WPTM is used expressing a large control energy consumed during TTM due to the high number of attempts performed by the flying model to track each segment in the desired trajectory segments. Figures $\mathbf{3 0}$ and $\mathbf{3 1}$ show that TTM would have longer endurance (5\% more) than the WPTM for the same range (or mission), consequently TTM would have less range than WPTM for a given amount of fuel.

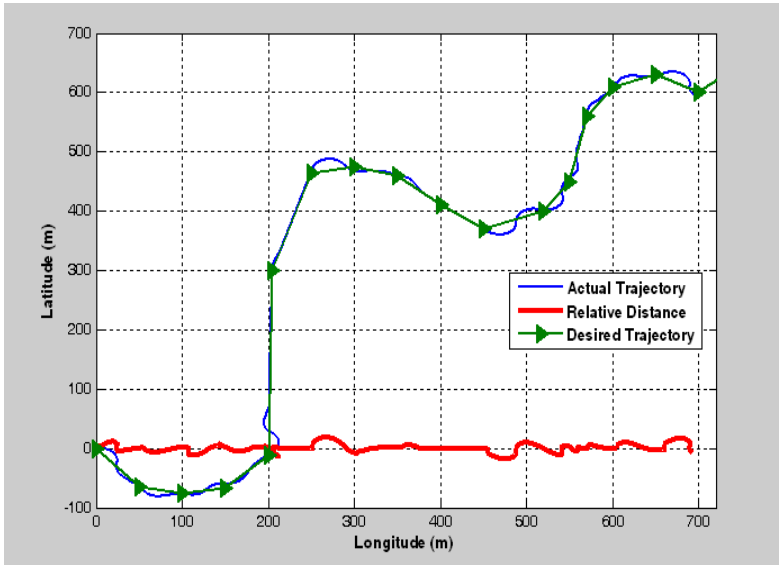

Fig. 12 Actual and Desired Trajectories in XY Plane with the Relative Lateral Distances (in DTCS body axis) for TTM

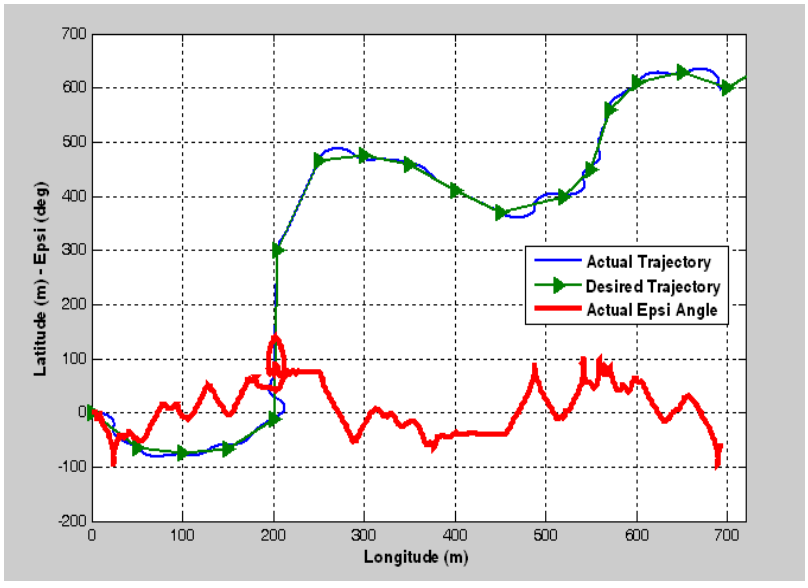

Fig. 14 Actual and Desired Trajectories with Actual Heading Angle For TTM

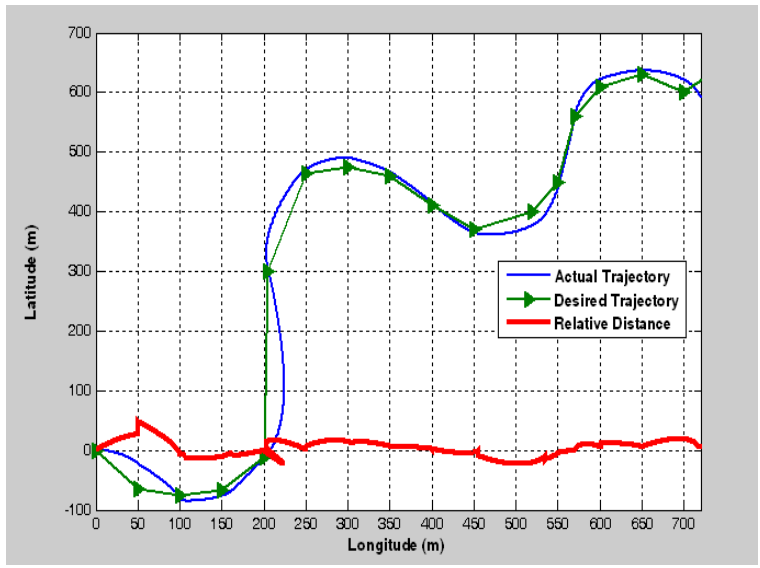

Fig. 13 Actual and Desired Trajectories in XY Plane with the Relative Lateral Distances (in DTCS body axis) for WPTM

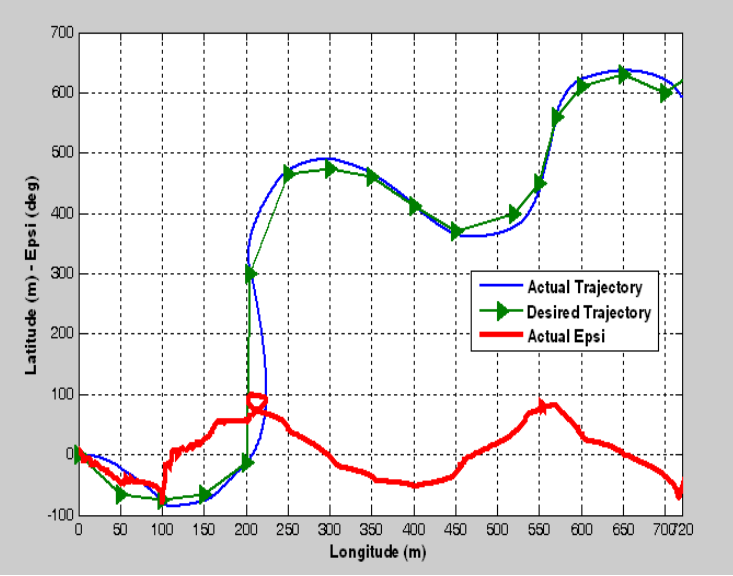

Fig. 15 Actual and Desired Trajectories with Actual Heading Angle For WPTM 


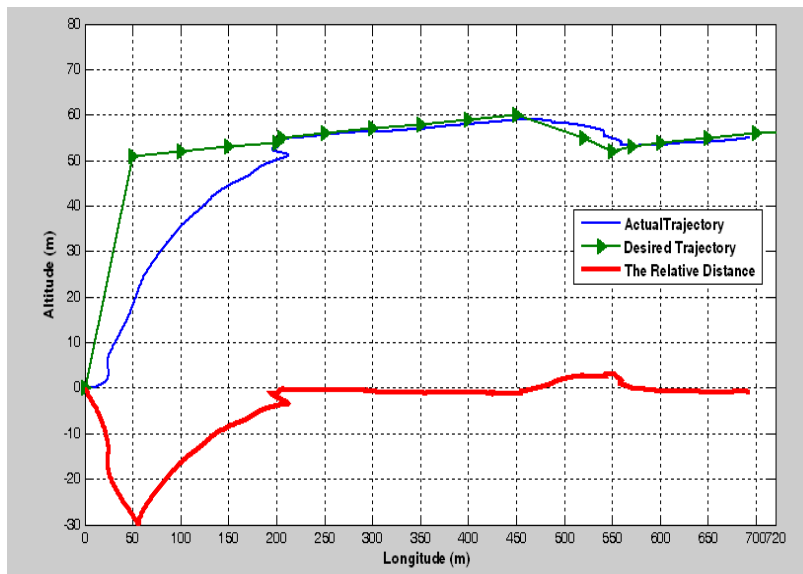

Fig. 16 Actual and Desired Trajectories in XZ Plane with the Relative Vertical Distances (in DTCS body axis) for TTM

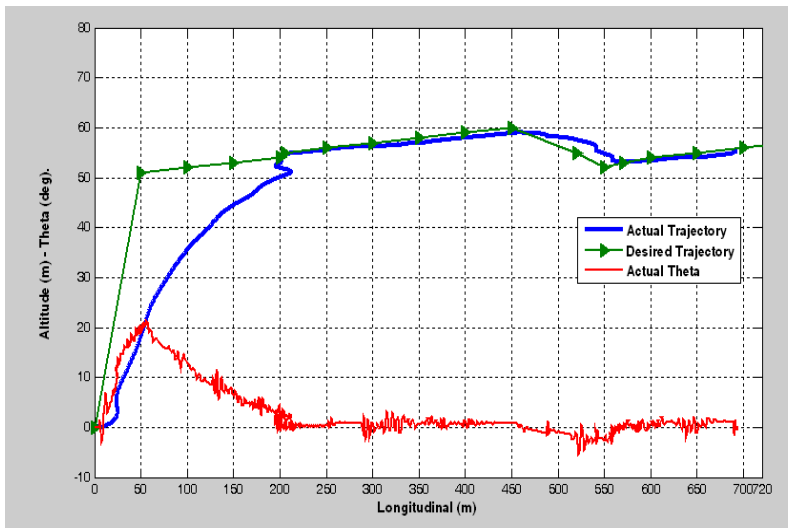

Fig. 18 Actual and Desired Trajectories in XZ Plane with Actual Elevation for TTM

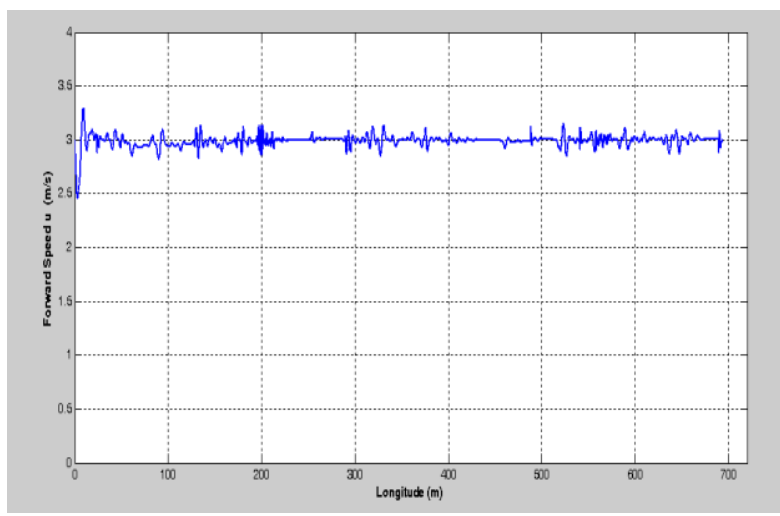

Fig. 20 Actual and Desired Forward Speed for TTM

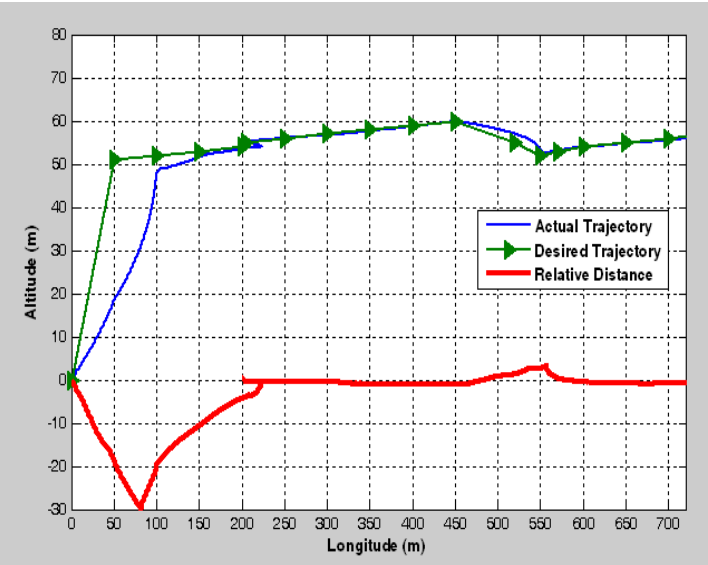

Fig. 17 Actual and Desired Trajectories in XZ Plane with the Relative Vertical Distances (in DTCS body axis) for WPTM

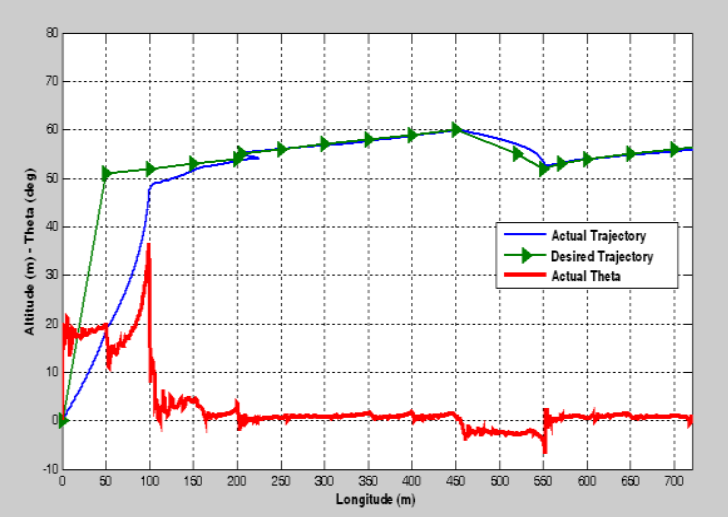

Fig. 19 Actual and Desired Trajectories in XZ Plane with Actual Elevation for WPTM

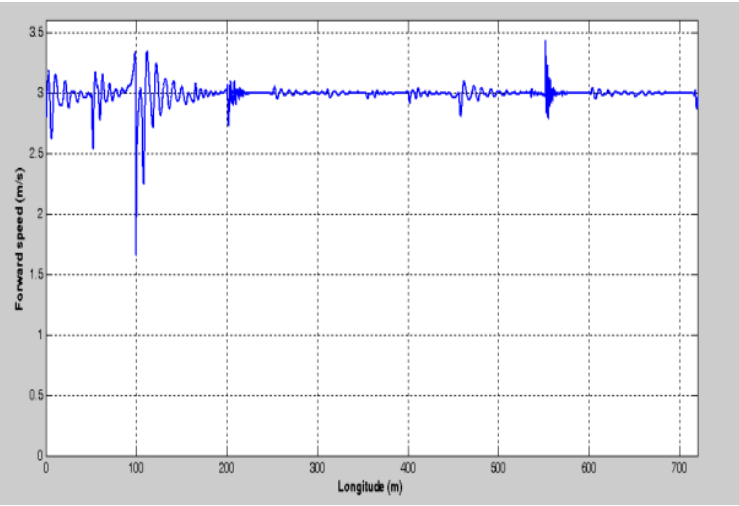

Fig. 21 Actual and Desired Forward Speed for WPTM 


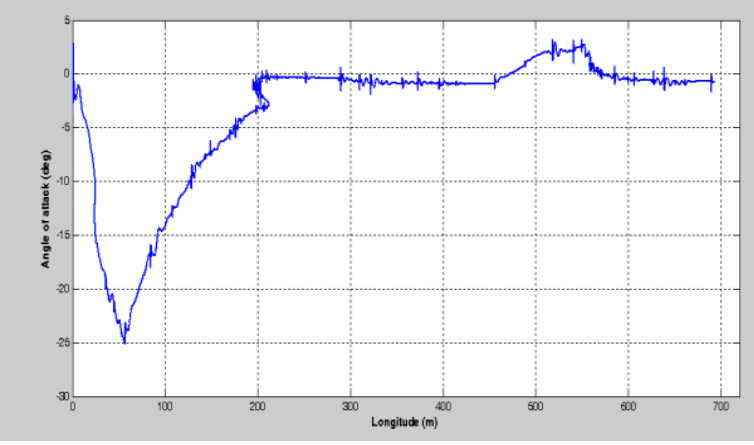

Fig. 22 Angle of Attack for TTM

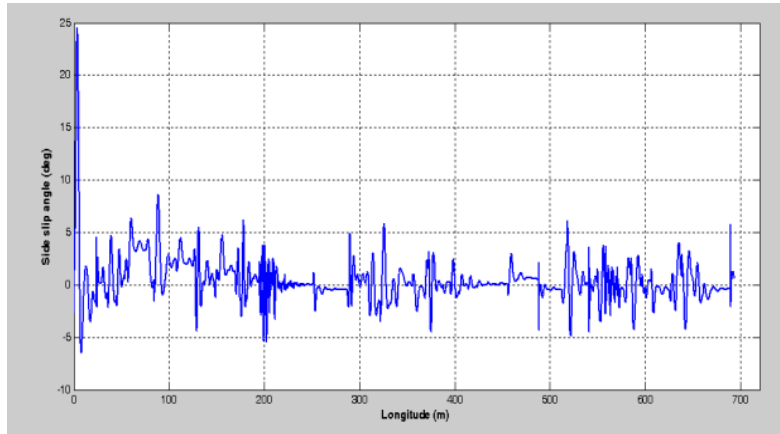

Fig. 24 Side Slip Angle for TTM

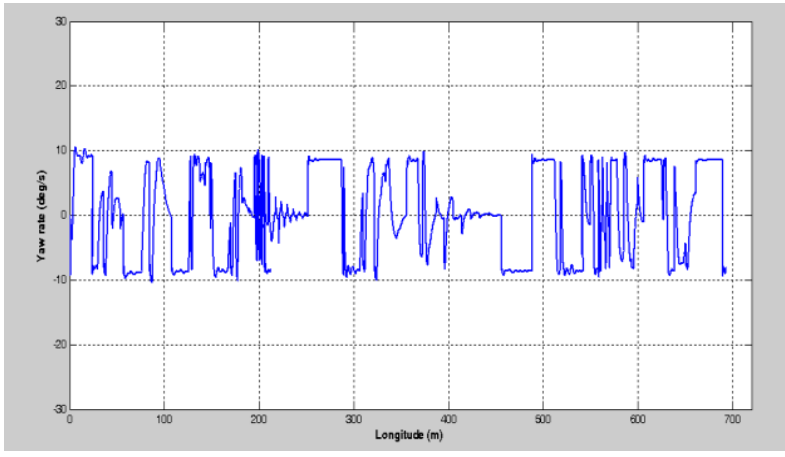

Fig. 26 Yaw Rate for TTM

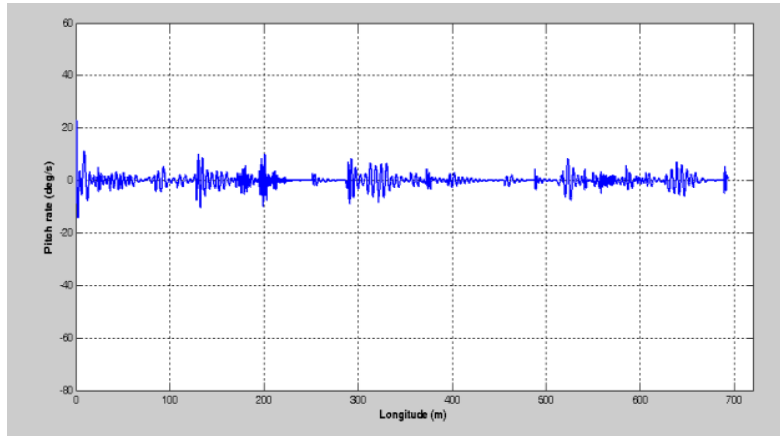

Fig. 28 Pitch Rate for TTM

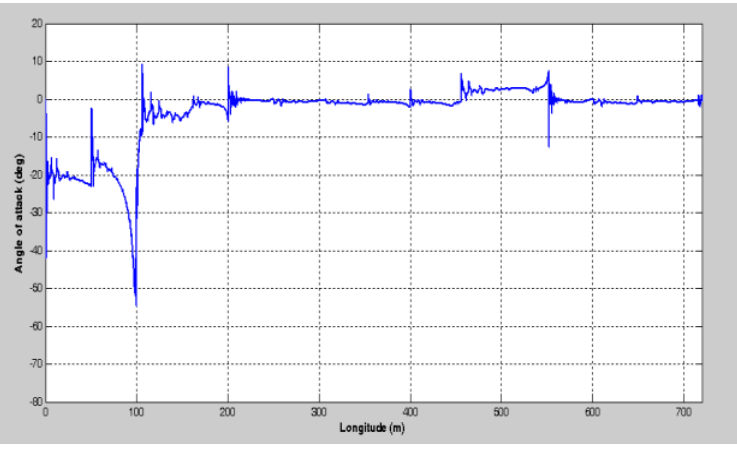

Fig. 23 Angle of Attack for WPTM

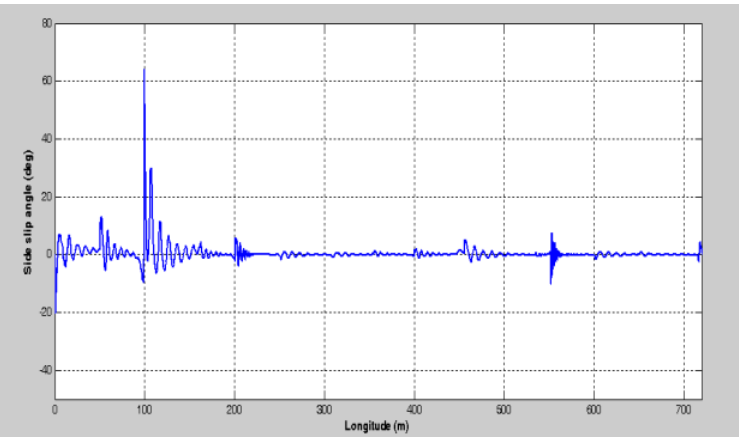

Fig. 25 Side Slip Angle for WPTM

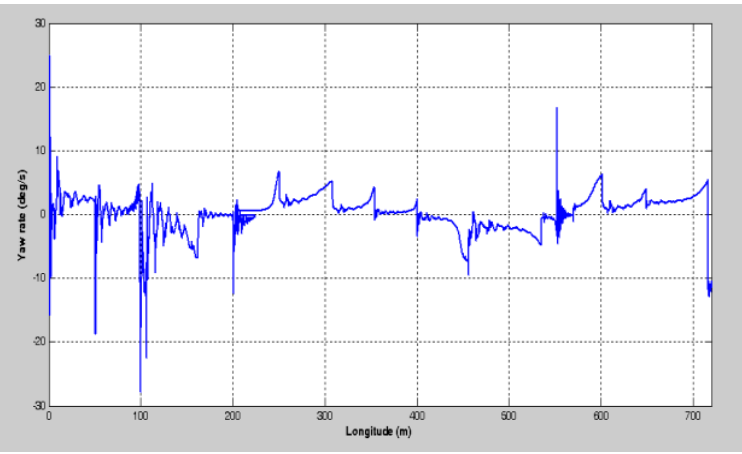

Fig. 27 Yaw Rate for WPTM

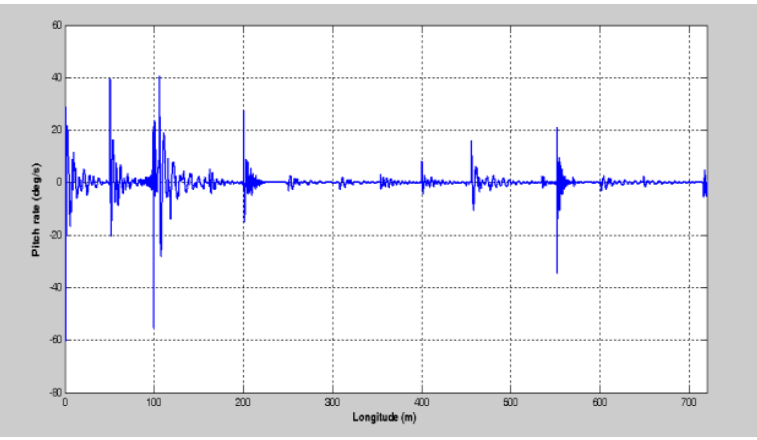

Fig. 29 Pitch Rate for WPTM 


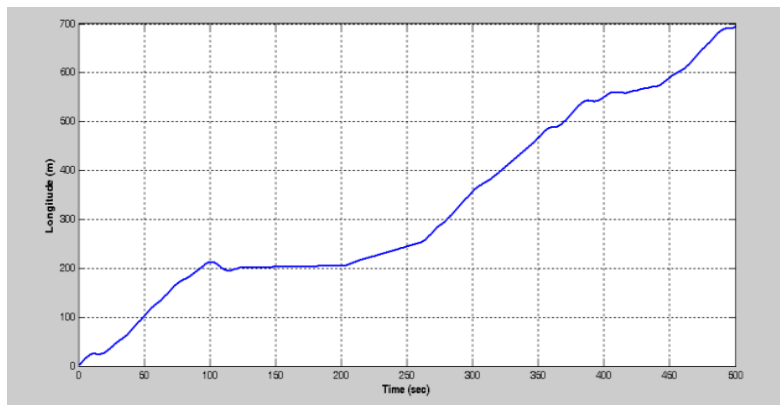

Fig. 30 Range and Endurance for TTM

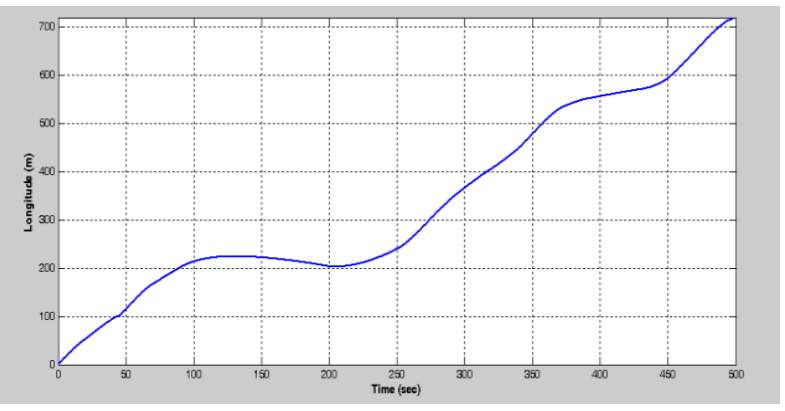

Fig. 31 Range and Endurance for WPTM

\section{Control System Performance}

Figures 32 through 39 illustrate the control efforts done by each servo to perform the maneuvers required for the desired flight path for both TTM and WPTM. Figure 38 indicates an obvious fluctuation with large amplitude that would need a considerable amount of electric energy. This number of fluctuations would reduce the servos life time, and decrease the mean time between failures.

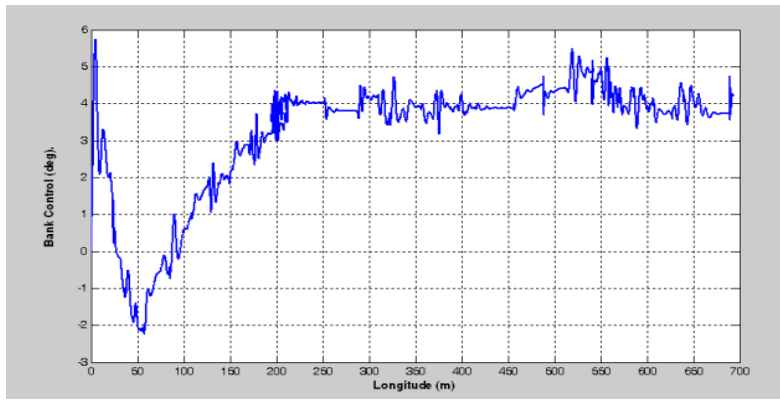

Fig. 32 Lateral Control Effort for TTM

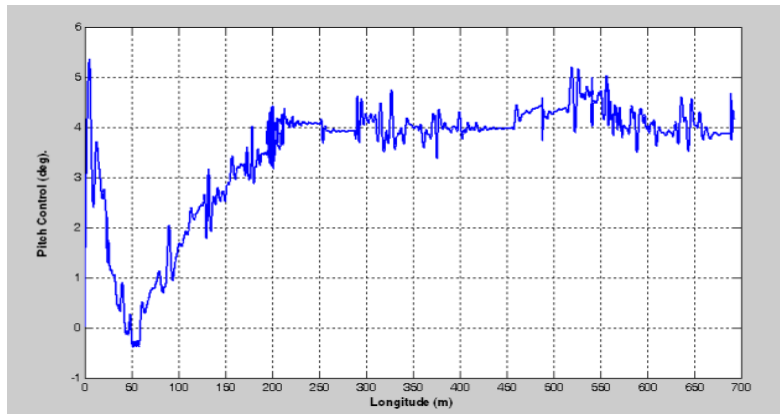

Fig. 34 Pitch Control Effort for TTM

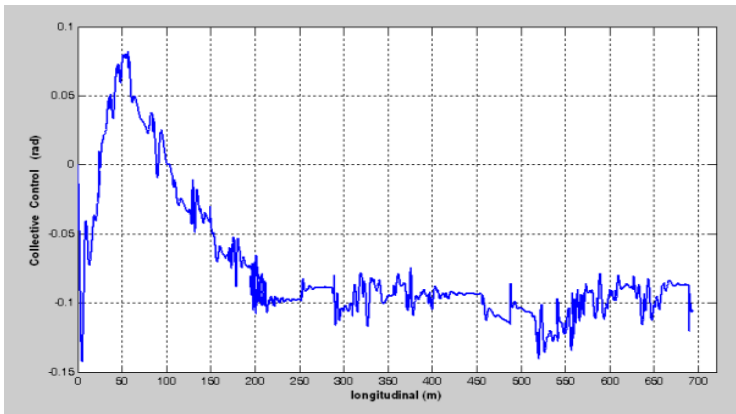

Fig. 36 Collective Control Effort for TTM

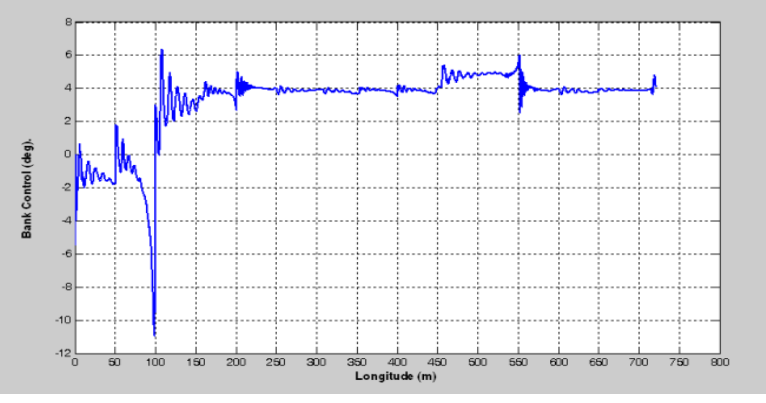

Fig. 33 Lateral Control Effort for WPTM

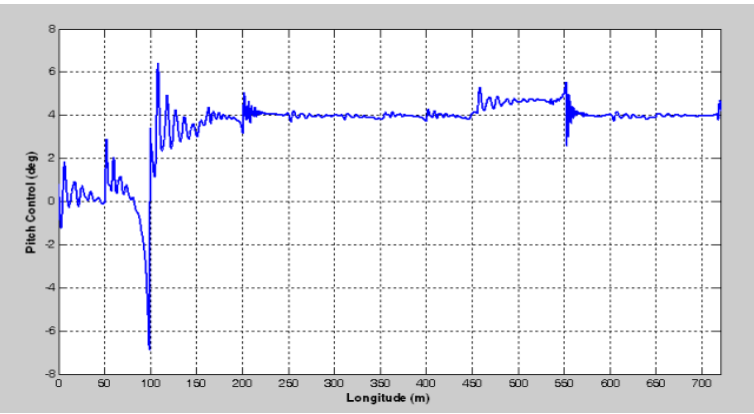

Fig. 35 Pitch Control Effort for WPTM

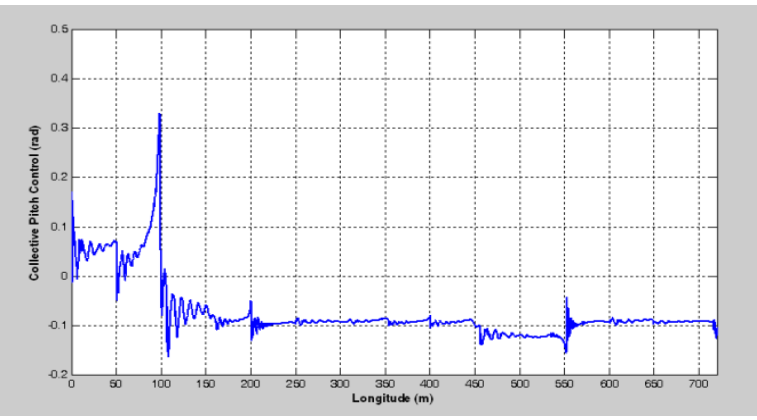

Fig. 37 Collective Control Effort for WPTM 


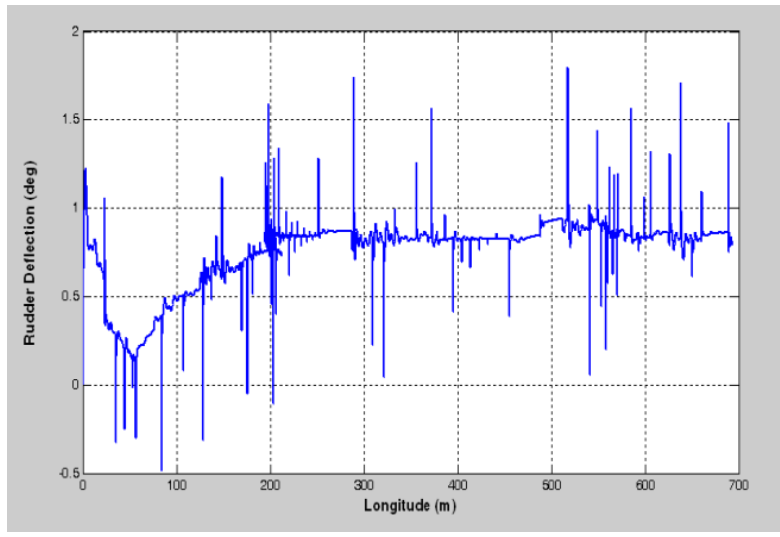

Fig. 38 Rudder Control Effort for TTM

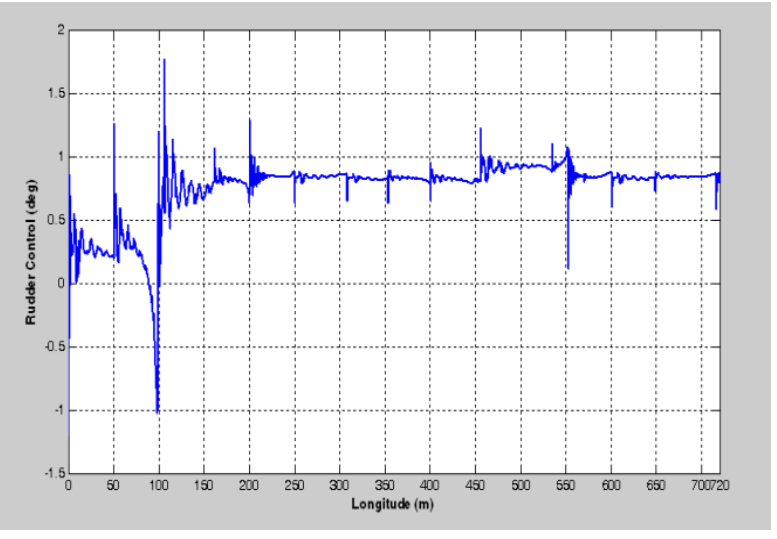

Fig. 39 Rudder Control Effort for WPTM

\section{System Evaluation}

The absolute relative distance integral in both (X, Y) directions (in DTCS body axis) was chosen to be the evaluation criteria (Performance Index PI) in this work. Figures $\mathbf{4 0}$ and $\mathbf{4 1}$ show that the Trajectory Tracking Method TTM has less (Performance Index PI) when it is compared with Waypoint Tracking Method WPTM though the (Performance Index PI) using WPTM is slightly less than when using TTM in Z direction (with respect to DTCS body axis). As the global performance index for both directions $\mathrm{Y}, \mathrm{Z}$ (with respect to DTCS body axis) using TTM is much less when compared with the WPTM. On the other hand when applying the same performance index to both methods (TTM, WPTM) for yaw rate, yaw acceleration and yaw jerk, it is clear that the TTM energy consumption during the tracking maneuvers is much more than the energy consumed by the WPTM as it is shown in Figs. 42, 43 and 44, $[4,5]$.

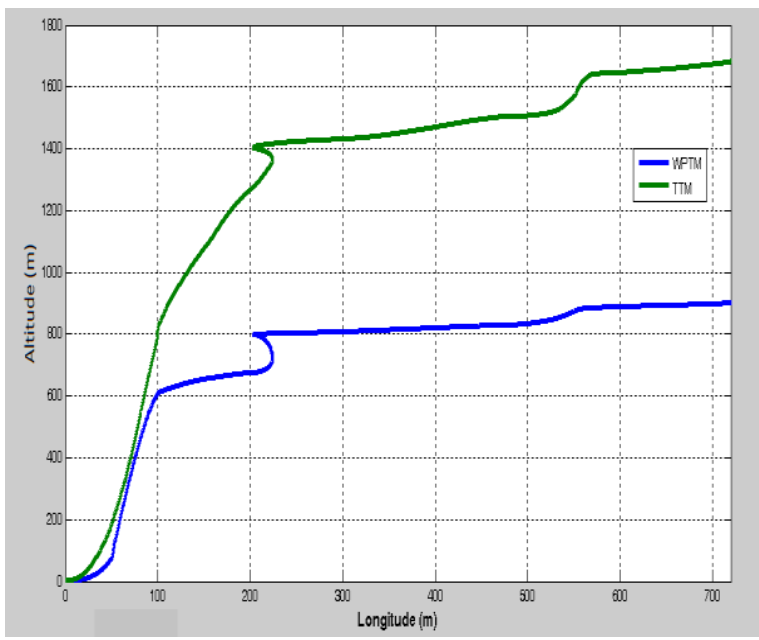

Fig. 40 Performance Index in $(Z)$ Directions for TTM and WPTM

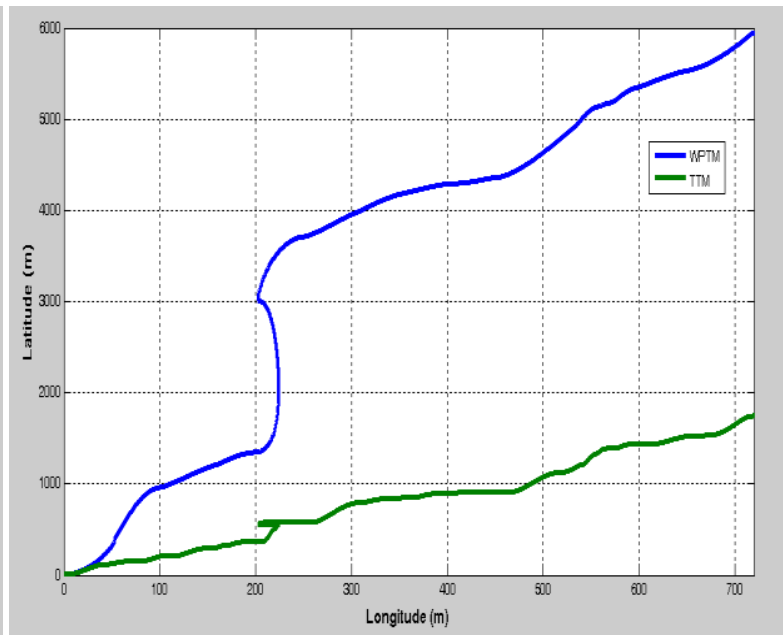

Fig. 41 Performance Index in (Y) Directions for TTM and WPTM 


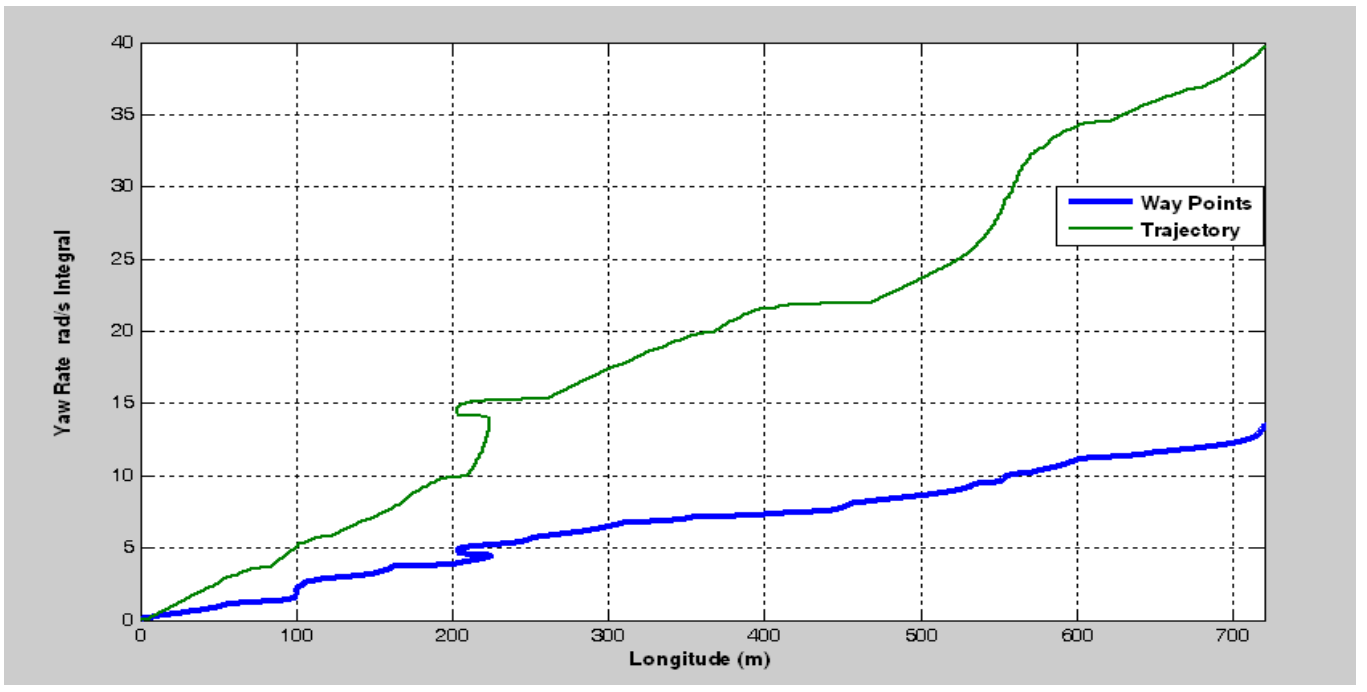

Fig. 42 Absolute Yaw Rate Integral for both TTM and WPTM

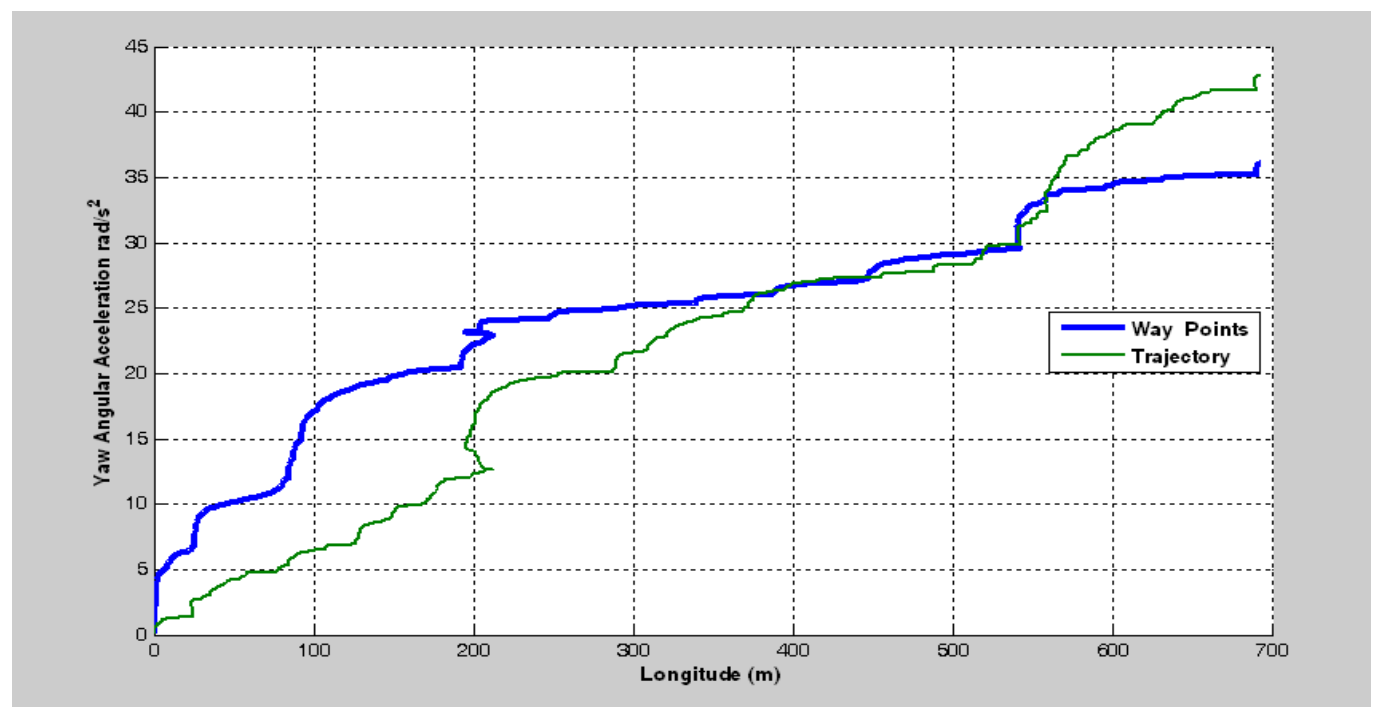

Fig. 43 Absolute Yaw Angular Acceleration Integral for both TTM and WPTM

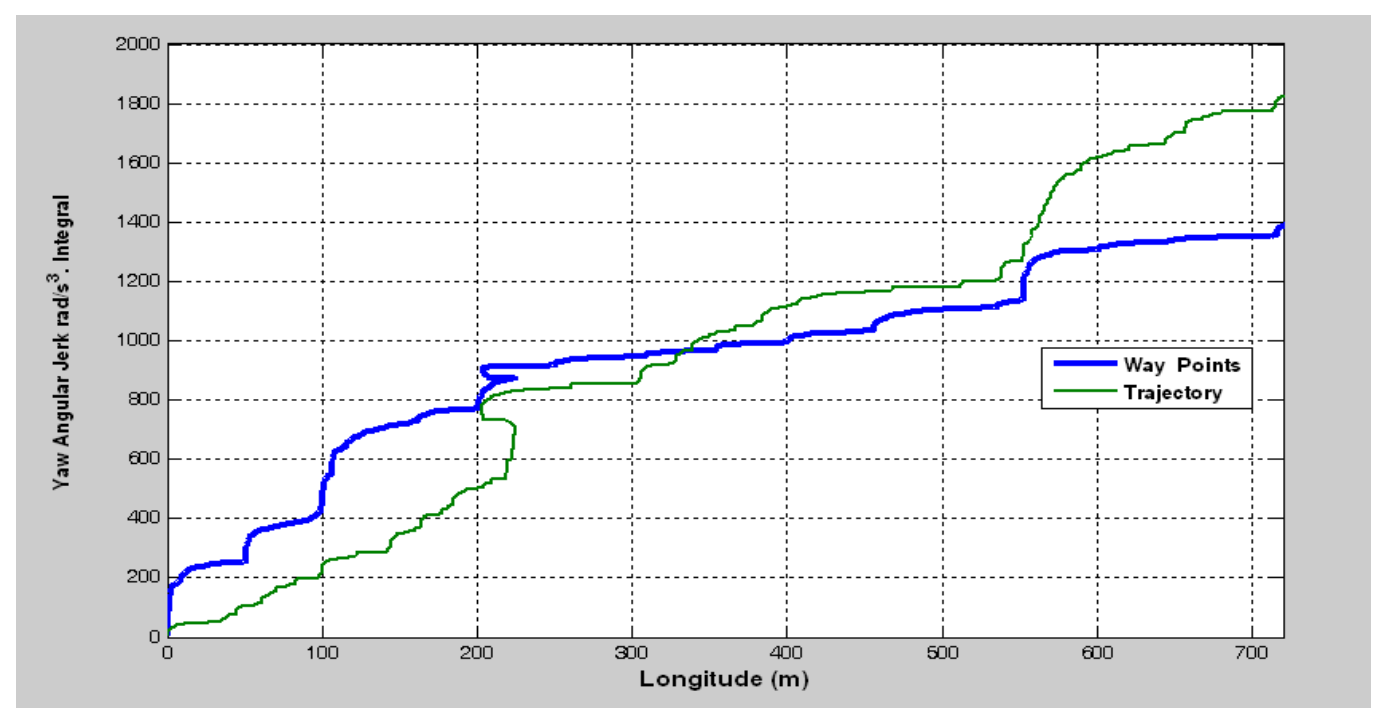

Fig. 44 Absolute Yaw Angular Jerk Integral for both TTM and WPTM 


\section{Conclusion}

This paper has presented a customized autopilot using PID controller combined with a guidance algorithm. Genetic algorithm was used in this work to tune the proposed stable state space model after applying pole placement method PPM. The proposed stable poles satisfy the flying qualities criteria. The illustrated results show an adequate system performance with a reasonable relative distances with respect to the desired trajectory. The forward speed was maintained constant during the whole flight according the desired speed. The servos control efforts are satisfying the band width limits, and also the minimum and maximum limits. It is concluded from the system performance that it is recommended to use TTM in case when the unmanned flying model is required to track a planned trajectory with less relative errors, while the WPTM is recommended when the precision in tracking the planned trajectory is not an objective. However the control energy consumed by TTM is obviou sly more than WPTM for the same planned trajectory (Flight Path), thus the control servos using TTM would require more batteries than they would require when using WPTM. The application of hybrid system that utilizes both methods advantages is strongly recommended in this case. Using both methods will allow applying TTM during loitering when the tracking precision is required, while applying WPTM when it is only required to pass the waypoints without tracking the flight path passing those waypoints (when covering distances only is required during flight).

\section{References}

[1] Shamsudin S. S., "The Development of Autopilot System for an Unmanned Aerial Vehicle (UAV) Helicopter Model”, M. Sc. thesis, Universiti Teknologi, Malaysia, Faculty of Mechanical Engineering. 2007, pp. 1-147.

[2] Hosny A. M., Chao H., "Development of Fuzzy Logic LQR Control Integration for Aerial Refueling Autopilot", "Proceedings of the $12^{\text {th }}$ International Conference on Aerospace Sciences and Aviation Technology, ASAT-12," , MTC, Cairo, Egypt, May 29-31, 2007.

[3] Hosny A. M., Chao H., "Fuzzy Logic Controller Tuning Via Adaptive Genetic Algorithm Applied to Aircraft Longitudinal Motion", " Proceedings of the $12^{\text {th }}$ International Conference on Aerospace Sciences and Aviation Technology, ASAT-12," MTC, Cairo, Egypt, May 29-31, 2007.

[4] Goldberg, D., Genetic Algorithms in Search, Optimization \& Machine Learning, ${ }^{\text {st }}$. ed., Vol. 1, Addison Wesley Longman, 1989.

[5] Flying Qualities of Aeronautical Design Standard for Military Helicopter (ADS-33C) (US Army Aviation Systems Command, 1989). 